\title{
Preparation and Characterization of Calcium Stearate Powders and Films Prepared by Precipitation and Langmuir-Blodgett Techniques
}

\author{
Mehmet Gönen, Serdar Öztürk, ${ }^{\dagger}$ Devrim Balköse, ${ }^{*}$ Salih Okur, and Semra Ülkü \\ Department of Chemical Engineering, İzmir Institute of Technology, Gülbahce Köyü Urla, \\ 35430 İmir, Turkey
}

\begin{abstract}
The preparation of calcium stearate $\left(\mathrm{CaSt}_{2}\right)$ using precipitation and Langmuir-Blodgett techniques was investigated in this study. While sodium stearate and calcium chloride were used in the precipitation process, calcium stearate nanofilms were produced from stearic acid and calcium chloride in sodium borate buffer with the Langmuir-Blodgett technique. Fourier transform infrared (FTIR) spectroscopy indicated carboxylate bands at 1577 and $1543 \mathrm{~cm}^{-1}$ in equal intensity in the powder form, but the films had a higher intensity 1577 $\mathrm{cm}^{-1}$ band than the $1543 \mathrm{~cm}^{-1}$ band. This showed the calcium ions associated with the $\mathrm{COO}^{-}$ions in the monodendate and bidendate structures in powders, and it was mainly in the bidendate structure in films. While characteristic peaks of $\mathrm{CaSt}_{2}$ at $2 \theta$ values of $6.40^{\circ}$ and $19.58^{\circ}$ were obtained in the X-ray diffraction (XRD) pattern of the dried powdered product, no sharp peaks were present in the 13 layer $\mathrm{CaSt}_{2}$ film. From scanning electron microscopy (SEM) micrographs, it was seen that calcium stearate powder had lamellar structure and the average particle size was $600 \mathrm{~nm}$. The AFM picture of the $\mathrm{CaSt}_{2}$ film indicated the surface was not smooth with a peak to valley distance of $6 \mathrm{~nm}$.
\end{abstract}

\section{Introduction}

The alkaline earth and transition metal salts of the fatty acids are called metal soap. ${ }^{1,2}$ Although the alkali salts of the fatty acids such as sodium $(\mathrm{Na})$ and potassium $(\mathrm{K})$ are water-soluble, metal soaps are water insoluble but more soluble in nonpolar organic solvents. These compounds have the general formula $\mathrm{M}\left(\mathrm{C}_{n} \mathrm{H}_{2 n+1} \mathrm{COO}\right)_{x} ; \mathrm{M}$ and $x$ refer to the metal ion and its charge, respectively. These long chain carboxylates of metal ions are compounds of considerable commercial importance and find applications in areas such as lubricant and stabilizer for rigid and flexible PVC, polyolefin acid scavenger, mold release agent in polymers; lubricant, free-flow promoter, anticaking agent in pharmaceuticals; waterproofing, flatting, and drier agents in coatings and paints; component of lubricating greases, catalyst and catalyst modification, fuel additives, and etc.

The precipitation process generally produces metal soap by the reaction of an aqueous solution of a water-soluble metal salt and a fatty acid alkali metal salt at a temperature below the boiling point of water under atmospheric pressure. Filtering, washing, and drying are the important steps in this method. Paulenat et al. ${ }^{2}$ reported $98.5 \%$ conversion of sodium soap upon calcium chloride addition.

Calcium stearate is usually produced by using the double decomposition (precipitation) process as shown in eq 1 .

$$
\begin{aligned}
2 \mathrm{C}_{17} \mathrm{H}_{35} \mathrm{COO}^{-+} \mathrm{Na}(\mathrm{aq}) & +\mathrm{Ca}^{2+}(\mathrm{aq}) \rightarrow \\
& \left(\mathrm{C}_{17} \mathrm{H}_{35} \mathrm{COO}\right)_{2} \mathrm{Ca}(\mathrm{s})+2 \mathrm{Na}^{+}(\mathrm{aq})
\end{aligned}
$$

The reaction can occur in two steps as shown by eqs 2 and 3 .

* To whom correspondence should be addressed. E-mail: devrimbalkose@iyte.edu.tr. Tel.: 00902327506642. Fax: 00902327506645 .

${ }^{\dagger}$ Present address: Serdar Öztürk, Ph.D. candidate, Research Assistant Room 309/Lab 312-314, Artie McFerrin Department of Chemical Engineering, Texas A\&M University, 3122 TAMU, College Station, Texas 77843-3122.

$$
\begin{aligned}
& \mathrm{NaSt}(\mathrm{aq})+\mathrm{CaCl}_{2}(\mathrm{aq}) \rightarrow \mathrm{CaStCl}(\mathrm{s})+\mathrm{NaCl}(\mathrm{aq}) \\
& \mathrm{CaStCl}(\mathrm{aq})+\mathrm{NaSt}(\mathrm{aq}) \rightarrow \mathrm{CaSt}_{2}(\mathrm{~s})+\mathrm{NaCl}(\mathrm{aq})
\end{aligned}
$$

where St represents the $\mathrm{C}_{17} \mathrm{H}_{35} \mathrm{COO}^{-}$ion.

Beneventi et al. ${ }^{3}$ has shown that solubility of calcium soaps was greatly influenced by the presence of unsaturations in the hydrocarbon chain: the higher the number of $\mathrm{C}=\mathrm{C}$ unsaturations, the higher the solubility of calcium soap. The solubility product of $\mathrm{CaSt}_{2}$ was reported as $10^{-14.8} \mathrm{~mol} / \mathrm{L}^{3}$.

$\mathrm{CaSt}_{2}$ is one of the important ionic surfactants of metal soaps. $\mathrm{CaSt}_{2}$ is recently used in the preparation of Langmuir-Blodgett (LB) mono and multilayers. ${ }^{4,5}$

The LB technique is currently employed to fabricate organized molecular layered structures of a variety of functionalized molecules. Long chain fatty acid/salts have been extensively studied with LB systems both as the Langmuir monolayer as well as LB multilayers. ${ }^{6}$ Stearic acid and divalent metal stearates are mostly studied subgroups of these chemical materials. ${ }^{5}$ Various properties of monolayers and LB films of these compounds such as composition, morphology, molecular structure, etc. were investigated by Bukreeva et al. ${ }^{7}$ Multilayers of zinc arachidate LB films were found to be crystalline with bilayer distance changing with preparation subphase $\mathrm{pH}^{8}{ }^{8} \mathrm{In}$ multilayer cadmium stearate Langmuir-Blodgett films, cadmium atoms are in the form of rectangular unit cells. ${ }^{9}$ During Langmuir-Blodget film formation, stearic acid dissolved in an organic solvent is spread on the surface of the water subphase. Then, it is neutralized by the base in aqueous phase forming water-soluble sodium soap as shown in eq 4 .

$$
\begin{array}{r}
\mathrm{C}_{17} \mathrm{H}_{35} \mathrm{COOH}(\mathrm{s})+\mathrm{Na}^{+-} \mathrm{OH}(\mathrm{aq}) \rightarrow \mathrm{C}_{17} \mathrm{H}_{35} \mathrm{COO}^{-+} \mathrm{Na}(\mathrm{aq})+ \\
\mathrm{H}_{2} \mathrm{O} \text { (4) }
\end{array}
$$

The sodium soap reacts with calcium ions to give calcium soap according to eq 1 .

The calcium stearate film formed on the surface of water is compressed and transferred to the surface of clean substrates 
to get a monolayer. During LB multilayer formation, each layer is dried in ambient air, sequentially.

One other way of preparing LB films of metal stearates is by dissolving in an organic solvent and spreading on water. Kundu dissolved iron stearate in chloroform and spread it on water. ${ }^{10}$

$\mathrm{Lu}$ and Miller ${ }^{11}$ characterized strongly adsorbed and LB transferred calcium carboxylates to a calcium flourite surface using in situ Fourier transform infrared (FTIR) spectroscopy. Bulk precipitated calcium dicarboxylate salts have an antisymmetric stretching vibration of the carboxylate group at 1540 and $1575 \mathrm{~cm}^{-1}$ belonging to unidendate and bidendate modes, respectively. On the other hand, LB films had a singlet peak at $1550 \mathrm{~cm}^{-1}$.

A quartz crystal microbalance study of LB films of calcium palmitate shows $1 \mathrm{~mol}$ of crystal water in its structure. ${ }^{12} \mathrm{LB}$ films of metal stearates have been used in humidity measurements. Electrical conductivity of $\mathrm{ZnSt}_{2} \mathrm{LB}$ films with 13 layers having $28 \mathrm{~nm}$ thickness was very sensitive to humidity above $40 \%$ at $25{ }^{\circ} \mathrm{C}$. The repeated experimental results showed no hysteresis during adsorption and desorption of water vapor. ${ }^{13}$

To the best of our knowledge, there has been little experimental data that exists on the characterization of both calcium stearate powders and LB films using sophisticated techniques such as atomic force microscopy (AFM), scanning electron microscopy (SEM), X-ray diffraction (XRD), and FTIR. This complementary investigation could be the primary step for further research on application of calcium stearate as a gas sensor for different organic analytes. Our previous experimental study demonstrated the sensitivity of zinc stearate films to humid air present in the atmosphere, making it good candidate for a humidity sensor. ${ }^{11}$ Thus in the present study, the preparation and characterization of pure calcium stearate in powder form and in LB film form were aimed to be investigated by FTIR spectroscopy, XRD, SEM, and AFM. While $\mathrm{CaSt}_{2}$ powder was obtained by the precipitation process from $\mathrm{NaSt}$ and $\mathrm{CaCl}_{2}$, multilayer thin films were transferred on the surface of silver coated glass slides.

\section{Experimental Techniques}

2.1. Materials. Calcium chloride, $\mathrm{CaCl}_{2} \cdot 2 \mathrm{H}_{2} \mathrm{O}(98 \%$, Aldrich), and sodium stearate, (NaSt) $\mathrm{C}_{17} \mathrm{H}_{35} \mathrm{COONa}$ (commercial product, Dalan Kimya A.Ş., Turkey), were used in the synthesis of $\mathrm{CaSt}_{2}$. The acid value of stearic acid, used in the $\mathrm{NaSt}$ synthesis, was $208.2 \mathrm{mg}$ of $\mathrm{KOH} / \mathrm{g}$ of stearic acid and it consists of a $\mathrm{C} 16-\mathrm{C} 18$ alkyl chain and with $47.7 \%$ and $52.3 \%$ by weight, respectively.

2.2. Precipitation Process. A total of $5.000 \mathrm{~g}(0.016 \mathrm{~mol})$ of sodium stearate $(\mathrm{NaSt})$ was dissolved in $200 \mathrm{~mL}$ of deionized water in the reactor at $75{ }^{\circ} \mathrm{C}$. Since the NaSt is partly soluble at low temperatures, the temperature of dissolution was selected as $75{ }^{\circ} \mathrm{C}$. A total of $1.7984 \mathrm{~g}(0.012 \mathrm{~mol})$ of calcium chloride (50\% excess) was dissolved in $100 \mathrm{~mL}$ of deionized water at $30{ }^{\circ} \mathrm{C}$ and added to the sodium soap solution at $75{ }^{\circ} \mathrm{C}$. The reaction temperature was maintained at $75{ }^{\circ} \mathrm{C}$ by a PID temperature controller (Love Controls series 2500). The mixture was stirred at a rate of $500 \mathrm{rpm}$ by a mechanical stirrer for 30 min. Since the byproduct, $\mathrm{NaCl}$, is soluble in water, the reaction media was filtered by using a Büchner funnel and flask under $600 \mathrm{mmHg}$ vacuum level. To remove the $\mathrm{NaCl}$ completely, wet $\mathrm{CaSt}_{2}$ was washed by $200 \mathrm{~mL}$ of deionized water once and then the wet $\mathrm{CaSt}_{2}$ cake was dried in a vacuum oven under $2 \times 10^{4}$ $\mathrm{Pa}$ pressure.

2.3. Langmuir-Blodgett Film Preparation. The KSV 3000 LB instrument with automated surface balance was used to form

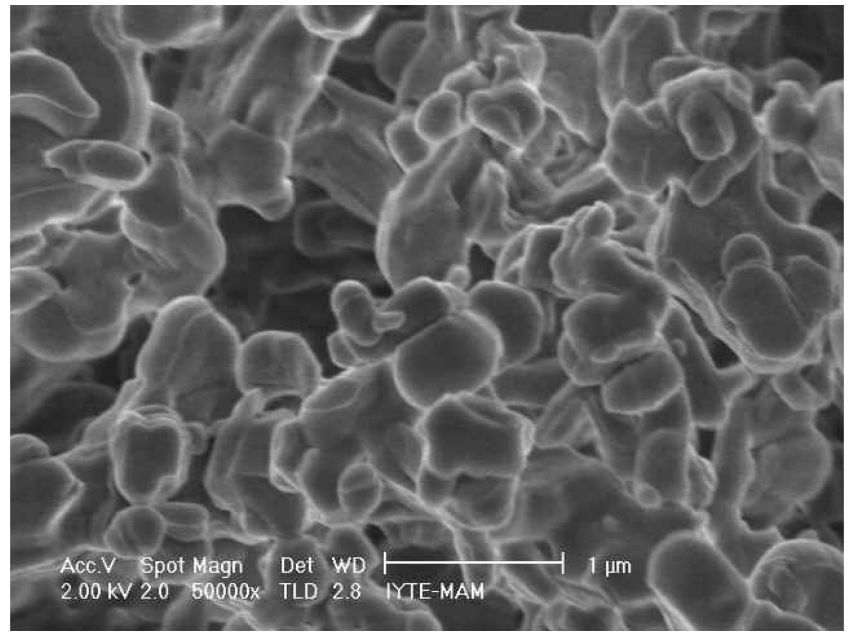

Figure 1. SEM Microphotograph of $\mathrm{CaSt}_{2}$ powder.

(a)

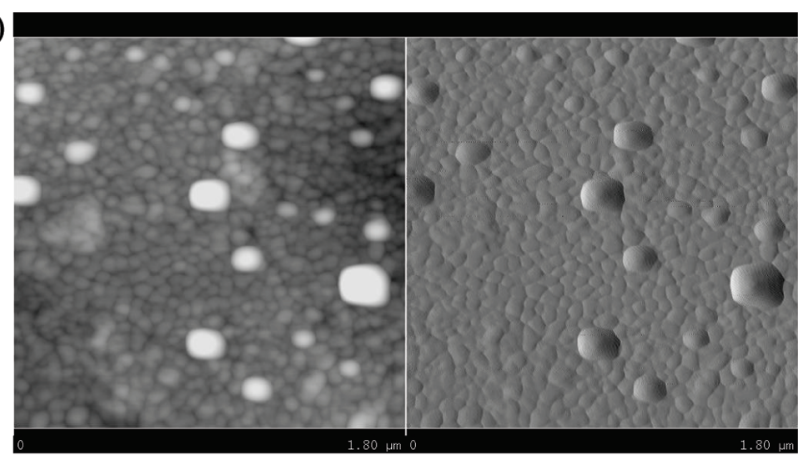

(b)

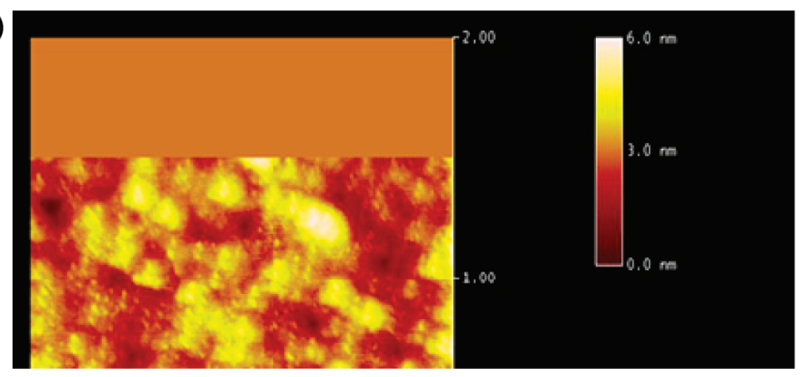

Figure 2. 2D and 3D Views (a) and depth profile (b) of the surface of the Langmuir-Blodgett film of calcium stearate obtained by AFM.

Langmuir-Blodgett films. Ultrapure water (with $18.3 \mathrm{M} \Omega \mathrm{cm}$ resistivity) deionized using the Elix 5 Milli-Q-Gradient Millipore system was used to prepare aqueous subphase solution. The glass substrates were purchased from Marienfeld. Stearic acid (>99.5\% , Fluka, 99\%, Nacalai) was used as a monolayer material. Benzene ( $>99.5 \%$, Riedel-deHaen) was employed as the spreading solvent. They were used as received without further purification. Calcium chloride (98-100.5\%, Merck) was added to the water subphase for calcium stearate monolayer deposition.

The glass substrates were cleaned in an ultrasonic bath with the sequence of solvents: acetone, 2-propanol, ethanol, and finally with $\mathrm{NaOH}(1 \mathrm{M})$. Then, the glass substrates were rinsed several times and kept in deionized water. In equipment cleaning, the barriers and Teflon trough were rinsed with pure deionized water after cleaning with acetone and ethanol before each experiment. The glass subsrates were coated with a thin $(80 \mathrm{~nm})$ silver film using a Leybold Uniwex 300 vacuum evaporator with a base pressure of $6 \times 10^{-5} \mathrm{~Pa}$. 


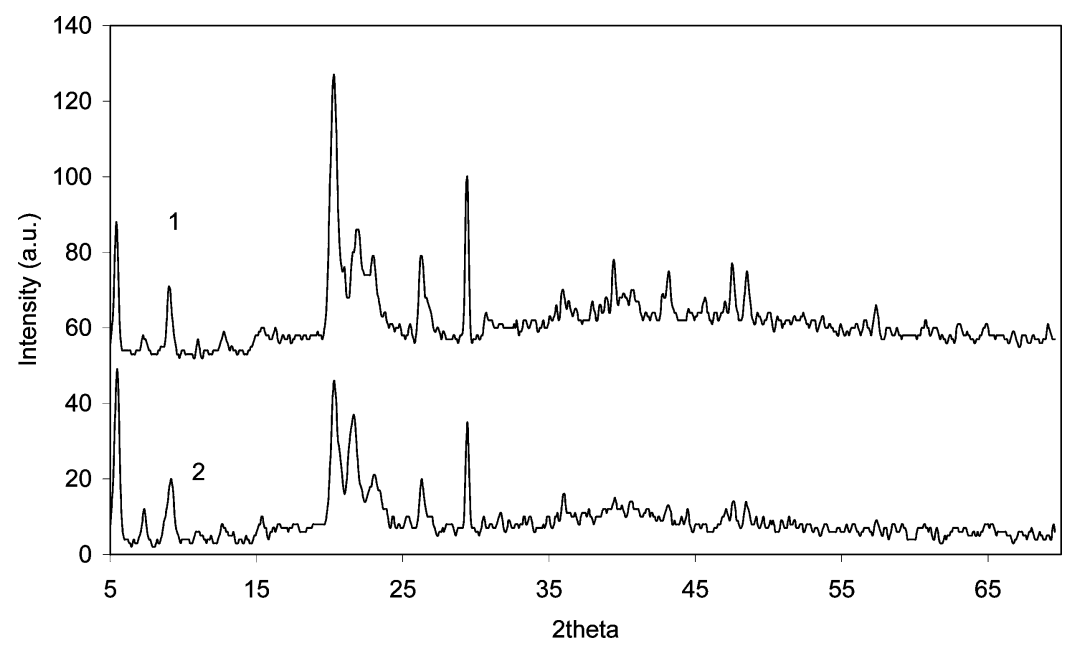

Figure 3. X-ray diffraction diagrams of precipitated $\mathrm{CaSt}_{2}$ from (1) $33 \%$ excess $\mathrm{Ca}$ and (2) $50 \%$ excess Ca.

Aqueous subphase surface cleaning prior to monolayer spreading was done by simply "washing" the subphase surface with benzene. A benzene solution of StAc with the concentration of $0.92 \mathrm{mg} / \mathrm{cm}^{3}$ was prepared as stock solution and stored at 4 ${ }^{\circ} \mathrm{C}$ in the refrigerator. A volume of $100 \mu \mathrm{L}$ of the solutions were spread by a Hamilton microliter syringe onto the subphase solution by distributing the droplets over the entire trough area at $20 \pm 0.5{ }^{\circ} \mathrm{C}$.

Monolayer formation by dissolving precipitated $\mathrm{CaSt}_{2}$ in chloroform similar to the successful study of $\mathrm{Kundu}^{10}$ failed due to solubility limitations. Thus monolayers were obtained from $10^{-4} \mathrm{~mol} \mathrm{dm}^{-3} \mathrm{CaCl}_{2}$ subphase solution having the $\mathrm{pH}$ regulated to 9.3 by using $1 \times 10^{-4} \mathrm{~mol} \mathrm{dm}^{-3}$ borate buffer. The spread monolayer solutions were allowed to evaporate for 30 min before compressing the monolayer to the desired target surface pressure value. Then, the monolayer were compressed with the rate of $3 \mathrm{~mm} / \mathrm{min}$ while the surface pressure was recorded using the Wilhelmy platinum plate with the resolution $0.004 \mathrm{mN} / \mathrm{m}$. At the target surface pressure, the monolayers were allowed to stabilize for 5 min before conventional dipping. Monolayers were deposited by the vertical dipping method onto silver coated glass slides at a constant surface pressure of 10 $\mathrm{mN} / \mathrm{m}$ with $2 \mathrm{~mm} / \mathrm{min}$ dipping speed.

The transfer ratios between 0.7 and 1.0 were obtained throughout the experiments. After the deposition of the first monolayer, LB films were kept dry in a desiccator with $\mathrm{P}_{2} \mathrm{O}_{5}$ for at least $15 \mathrm{~h}$ and then 12 more layers were transferred. Moreover, during multilayer transfer, the substrate with LB film was dried between each cycle for $20 \mathrm{~min}$ in air. The produced multi LB layers of $\mathrm{CaSt}_{2}$ were finally stored in a $\mathrm{P}_{2} \mathrm{O}_{5}$ desiccator prior to characterization. $\mathrm{Y}$ type deposition was obtained by this technique. ${ }^{14}$

2.4. Characterization of $\mathrm{CaSt}_{2}$ Powder. The crystalline structure and purity of the $\mathrm{CaSt}_{2}$ samples were determined by means of a X-ray powder diffractometer (Philips Xpert-Pro) with $\mathrm{CuK} \alpha$ radiation at $45 \mathrm{kV}$ and $40 \mathrm{~mA}$. The $\mathrm{X}$-ray scans were performed in the $5-60^{\circ} 2 \theta$ range. Scanning electron microscopy (Philips XL30 SFEG) with energy dispersive X-ray (EDX) analyses were used for the identification of particle size and product purity. The samples were coated with gold and palladium metals by using the sputtering technique. A Fourier transform infrared spectrophotometer (Shimadzu 8601) was used to obtain FTIR spectra of products. In the preparation of $\mathrm{CaSt}_{2}$ samples, the $\mathrm{KBr}$ disk method was used. A total of $4.0 \mathrm{mg}$ of $\mathrm{CaSt}_{2}$ and $196 \mathrm{mg}$ of $\mathrm{KBr}$ were mixed and pressed into $1 \mathrm{~cm}$ discs under 10 tons load. Energy dispersive X-ray analysis was used to determine the product constituents and the removal of byproduct, $\mathrm{NaCl}$.

2.5. Characterization of LB Films. The intralayer structure of the LB films was determined by using an X-ray powder diffractometer (Phillips X'Pert Pro) using a grazing incidence attachment at $20^{\circ} \mathrm{C}$. CuK $\alpha$ radiation with a Ni filter was used at $45 \mathrm{kV}$ and $40 \mathrm{~mA}$. Each scan was performed in the $2-70^{\circ}$ $2 \theta$ range.

The infrared spectra of LB films were taken by a specular reflectance accessory with $80^{\circ}$ (Pike Technologies) in the reflection-absorption mode with an Excalibur DIGILAB FTS 3000 MX type Fourier transform infrared spectrophotometer at $20{ }^{\circ} \mathrm{C}$ with a resolution of $4 \mathrm{~cm}^{-1}$. The DTGS type detector was used for all measurements. The background spectrum was obtained using a silver coated glass surface. A total of 50 scans were accumulated for the background and LB films. AFM measurements were performed to observe the topography of the calcium stearate films on silver coated glass substrates by using an atomic force microscope Nanoscope IV in the tapping mode.

\section{Results and Discussion}

3.1. Morphology. 3.1.1. Morphology of Particles. The crystal morphology of $\mathrm{CaSt}_{2}$ powder produced by the precipitation process is given as SEM microphotograph in Figure 1. The particles have random platelike shapes with an average size around $600 \mathrm{~nm}$.

3.1.2. Morphology of LB Film. A 2D and 3D AFM picture of the monolayer of $\mathrm{CaSt}_{2}$ films on silver coated films obtained by the tapping mode with the Nanoscope IV are shown in Figure 2a. The surface formed by the cohesion of particles having a $60 \mathrm{~nm}$ average size. The maximum particle size was $180 \mathrm{~nm}$. The $\mathrm{CaSt}_{2}$ films covered the entire $\mathrm{Ag}$ surface with a $6 \mathrm{~nm}$ valley to peak distance as seen in Figure $2 \mathrm{~b}$.

3.2. Crystal Structure. 3.2.1. Crystal Structure of the Particles. The X-ray diffraction patterns of $\mathrm{Ca}$ soaps obtained by the precipitation process with 50 and $30 \%$ excess $\mathrm{Ca}$ ions are shown in Figure 3. There are diffraction peaks at $2 \theta$ values $5.5^{\circ}, 7.42^{\circ}, 9.10^{\circ}, 11.02^{\circ}, 12.86^{\circ}$, and $15.58^{\circ}$ corresponding to third, fourth, fifth, sixth, seventh, and eighth order diffractions of the bilayer distance. From Braggs law and higher order reflection's $2 \theta$ values, the bilayer distance of precipitated calcium stearate was found as $4.8 \mathrm{~nm}$.

3.2.2. Crystal Structure of the LB Film. The X-ray diffraction diagram of the LB film of calcium stearate seen in Figure 4 was drawn after curve smoothing. The peaks observed 


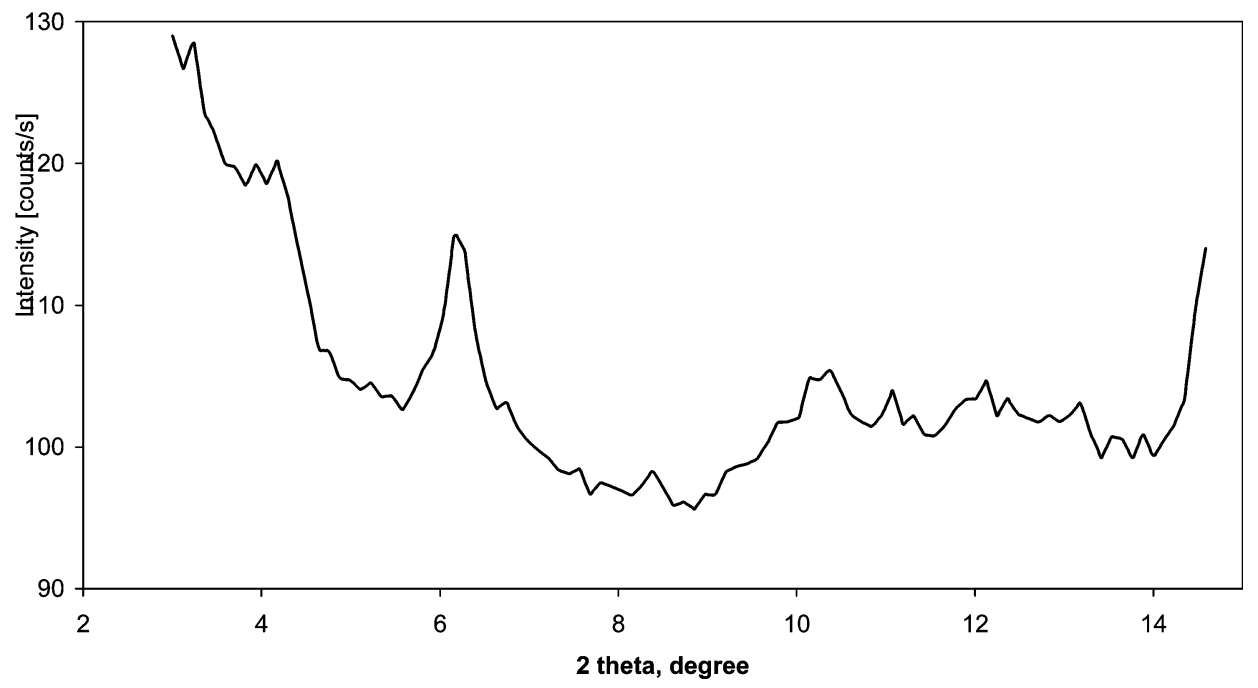

Figure 4. X-ray diffraction diagram of the Langmuir-Blodgett film of calcium stearate.

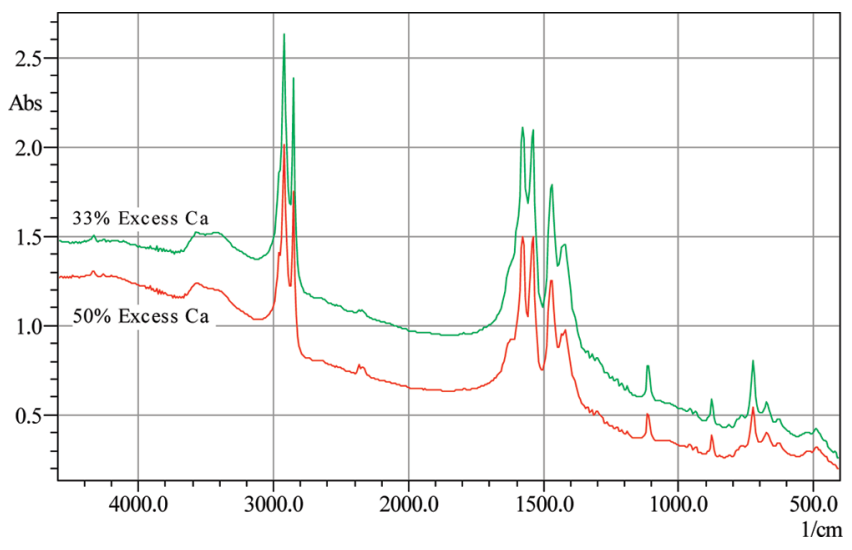

Figure 5. FTIR spectra of calcium stearate powder obtained by the precipitation process for $33 \%$ and $50 \%$ excess Ca.

at $2 \theta$ values of $4.2,6.2,8.2$, and 10.3 belonged to the second, third, fourth, and fifth order diffractions of the bilayer distance. From Bragg's law, the bilayer distance was found as $4.0 \mathrm{~nm}$, which corresponds to a $27^{\circ}$ chain tilt angle. LB films of other metal soaps such as $\mathrm{ZnSt}_{2}{ }^{13}$ and zinc arachidate ${ }^{8}$ had a $31^{\circ}$ chain tilt angle which is comparable to that found for $\mathrm{CaSt}_{2}$ in the present study.

3.3. FTIR Analysis. 3.3.1. FTIR Spectra of Calcium Stearate Powders. FTIR spectra of calcium stearate powders produced in the precipitation process are shown in Figure 5, and they are very similar to spectra of bulk $\mathrm{CaSt}_{2}$ spectra reported in previous studies. ${ }^{11}$ The characteristic peaks of calcium stearate at 1542 and $1575 \mathrm{~cm}^{-1}$ were observed. These bands are due to antisymmetric stretching bands for unidendate and bidendate association with calcium ions. Antisymmetric and symmetric methylene stretching, and methylene scissoring bands $\left(v_{\mathrm{a}} \mathrm{CH}_{2}, \nu_{\mathrm{s}} \mathrm{CH}_{2}\right.$, and $\left.\delta_{\mathrm{s}} \mathrm{CH}_{2}\right)$ were observed at about 2914, 2850, and $1472 \mathrm{~cm}^{-1}$, respectively. These bands are due to the alkyl chain in the calcium stearate structure.

3.3.2. FTIR Spectrum of Calcium Stearate LB Film. FTIR spectrum of the calcium stearate Langmuir-Blodgett film obtained by the specular reflectance attachment is depicted in Figure 6. Two peaks at about 2919 and $2852 \mathrm{~cm}^{-1}$, which are comparable with those of antisymmetric $\left(2962 \mathrm{~cm}^{-1}\right)$ and symmetric $\left(2876 \mathrm{~cm}^{-1}\right)$ methyl stretching bands $\left(\nu_{\mathrm{a}} \mathrm{CH}_{3}\right.$ and $\left.v_{\mathrm{s}} \mathrm{CH}_{3}\right)$ are seen, respectively. The LB film prepared in the present study shows peaks at 1577 and $1544 \mathrm{~cm}^{-1}$ assignable to the antisymmetric $\nu_{\mathrm{a}} \mathrm{COO}^{-}$stretching vibration of carboylate groups in unidendate and bidendate coordination with calcium ions, respectively. ${ }^{5,11} \mathrm{Lu}$ and Miller reported only one antisymmetric $\mathrm{COO}^{-}$peak at $1550 \mathrm{~cm}^{-1}$ in FTIR spectra of LB films on a calcium flourite surface, and $\mathrm{CaSt}_{2}$ was in the bidendate form. ${ }^{11}$ Since the intensity of the peak at $1577 \mathrm{~cm}^{-1}$ was higher than that of $1544 \mathrm{~cm}^{-1}$, carboxylate groups were mostly present

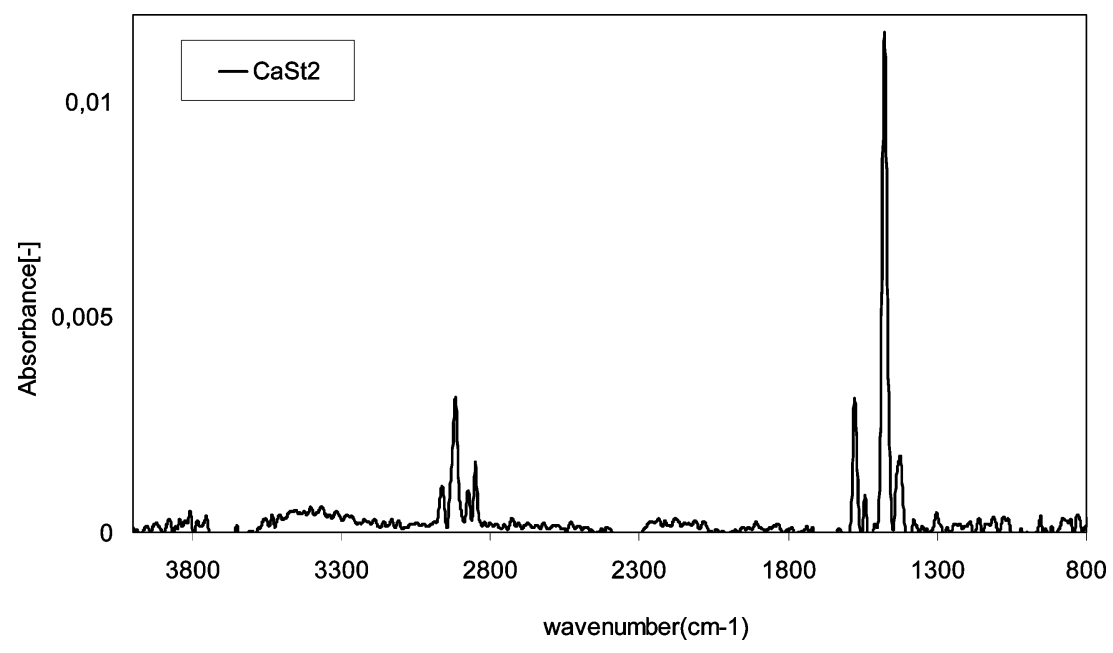

Figure 6. Specular reflectance spectrum of the Langmuir-Blodget film of calcium stearate. 
Table 1. Elemental Composition (On Hydrogen Free Basis) of $\mathrm{CaSt}_{2}$ Powders

\begin{tabular}{ccc}
\hline elements & $50 \%$ excess $\mathrm{Ca}$ & $33 \%$ excess $\mathrm{Ca}$ \\
\hline $\mathrm{Ca}(\%)$ & 6.05 & 5.02 \\
$\mathrm{C}(\%)$ & 82.74 & 83.74 \\
$\mathrm{O}(\%)$ & 10.59 & 10.46 \\
$\mathrm{Na}(\%)$ & 0.30 & 0.40 \\
$\mathrm{Cl}(\%)$ & 0.31 & 0.37
\end{tabular}

in the bidendate or chelating structure in the present study. The difference in coordination of $\mathrm{Ca}$ ions on the surface of $\mathrm{CaF}$ and Ag surfaces could be attributed to the different characteristics of the surfaces. In the $\mathrm{CaF}$ surface, there are also $\mathrm{Ca}$ ions to coordinate with carboylate groups and the Ag metal does not react with the carboxylate ions. Thus the coated film carries the characteristics of the bulk $\mathrm{CaSt}_{2}$. The possibility of the presence of crystal water in the LB film of calcium stearate, as reported for the calcium palmitate film, ${ }^{12}$ was eliminated since there was no peak at $1600 \mathrm{~cm}^{-1}$ due to the bending vibration of water molecules in the FTIR spectrum in Figure 6. The drying procedure used in the present study removed even crystal water from the calcium stearate. All carboxylic acid groups were converted to carboxylate ions as shown by eq 4 , since there were no $\mathrm{C}=\mathrm{O}$ peaks at $1740 \mathrm{~cm}^{-1}$ in the FTIR spectrum.

3.4. Product Purity of $\mathrm{CaSt}_{2}$ Powders. The formation of intermediate $\mathrm{CaStCl}$ shown by eq 1 and the presence of $\mathrm{Na}$ and $\mathrm{Cl}$ ions due to an incomplete washing process were possible in $\mathrm{CaSt}_{2}$ powder production. Thus the powders were analyzed by EDX, and their compositions are reported in Table 1 . There are approximately $6 \% \mathrm{Ca}, 83 \% \mathrm{C}$, and $11 \% \mathrm{O}$ on a hydrogen free basis for both excess $\mathrm{Ca}$ concentrations. The empirical formula found from this composition was $\mathrm{CaSt}_{2}$ indicating other possible stoichiometric compounds shown by eq 1, such as $\mathrm{CaStCl}$, did not form under these conditions. There were negligible amounts of sodium and chloride ions in the products indicating high efficiency of the washing process.

\section{Conclusions}

SEM micrographs of calcium stearate powder showed that crystal morphology is in the lamellar form. The particle size was found around $600 \mathrm{~nm}$. From Bragg's law and higher order reflection's $2 \theta$ values, the bilayer distances of calcium stearate powder and calcium stearate LB film were found as 4.8 and $4.0 \mathrm{~nm}$, respectively, by X-ray diffraction. The bands at 1542 and $1575 \mathrm{~cm}^{-1}$ in the FTIR spectra of the powders showed unidendate and bidendate association of stearate ions with calcium ions. EDX analysis showed highly pure calcium stearate powder was obtained from the precipitation process.

The surface of $\mathrm{CaSt}_{2} \mathrm{LB}$ films covered the entire Ag surface on the glass slides with a $6 \mathrm{~nm}$ valley to peak distance by cohesion of $60 \mathrm{~nm}$ average sized particles. Carboxlate groups might be present in the bidendate or chleating structure in the LB film, since the intensity of the peak at $1577 \mathrm{~cm}^{-1}$ was higher than that of $1544 \mathrm{~cm}^{-1}$.

While pure $\mathrm{CaSt}_{2}$ in the powder form can be used in the polymer processing and pharmaceutical industry, in lubricant production, and as catalyst, the LB films on silver coated glass slides could find applications in gas sensor, humidity measuring probe development.

\section{Acknowledgment}

The authors acknowledge The Scientific and Technical Research Council of Turkey (TÜBITAK) and State Planning Organization for the financial support from Projects MISAG185 and DPT2002K120390, respectively. We thank to Prof. J. Umemura for the valuable suggestions in preparation of the LB films.

\section{Literature Cited}

(1) Ishioka, T.; Maeda, K.; Watanabe, I.; Kawauchi, S.; Harada, M. Infrared and XAFS study on structure and transition behavior of zinc stearate. Spectrochim. Acta, Part A 2000, 56, 1736.

(2) Paulenat, G.; Sentenac, S.; Mouloungui, Z. Double Decomposition Reactions of Alkaline and Alkaline-Earth Oleic Soaps Under Salting Out Conditions. Ind. Eng. Chem. Res. 2004, 43, 1579.

(3) Benventi, D.; Carre, B.; Gandini, A. Precipitation and Solubility of Calcium Soaps in Basic Aqueous Media. J. Colloid Interface Sci. 2001, 237,142

(4) Kimura, F.; Umemura, J.; Takenaka, T. FTIR-ATR Studies on Langmuir-Blodgett Films of Stearic Acid with 1-9 Monolayers. Langmuir 1986, $2,96$.

(5) Sakai, H.; Umemura, J. Evaluation of molecular structure in Langmuir monolayers of zinc stearate and zinc 12-hydroxystearate by IR external reflection spectroscopy. Colloid Polym. Sci. 2002, 280, 316.

(6) Pignatora, B.; Consolva, C.; Compagnini, G.; Licciardello, A. Barium Stearate Langmuir Blodgett Films by Mapping Adhesion Forces with Atomic Microscopy. Chem. Phys. Lett. 1999, 299, 430.

(7) Bukreva, T. V.; Arslanov, V. V.; Gugina, I. A. Langmuir Blodgett Film of Fatty Acid Salts of Bi and Trivalent Metals: Y, Ba, Cu Stearates. Colloid J. 2003, 65-2, 134.

(8) Dhanabalan, A.; Kumar, N. P.; Major, S.; Talwar, S. S. Variation of Monolayer Behavior and Molecular packing in Zinc Arachidate LB films with subphase pH. Thin Solid Films 1998, 327-329, 787.

(9) Peng, J. R.; Burnes, G. T.; Gentle, R.; Foarn, G. J. Superstructure and Correlated Metal Ion Layers in Langmuir-Blodgett Films of Cadmium Soaps Observed with Grazing Incidance X-ray Diffraction. J. Phys. Chem. 2000, 104, 5533 .

(10) Kundu, S. Langmuir-Blodget film from a bi-molecular layer at air-water interface. Colloids Surf., A 2008, 317, 618.

(11) Lu, Y.; Miller, J. D. Carboxyl stretching vibrations of spontaneously adsorbed and LB_transferred calcium carboxylates as determined by FTIR internal reflection spectroscopy. J. Colloid Interface Sci. 2002, 256, 41.

(12) Seo, B. L.; Lee, H.; Chung, J. J.; Cha, S. H.; Lee, K. H.; Seo, W. J.; Cho, Y.; Park, H. B.; Kim, W. S. Hydration number of calcium palmitate LB film deposited on a piezoelectric quartz crystal balance. Thin Solid Films 2002, 327-329, 722.

(13) Öztürk, S.; Balköse, D.; Okur, S.; Umemura, J. Effect of humidity on electrical conductivity of zinc stearate nanofilms. Colloids Surf., A 2007, $302,67$.

(14) Özturk, S. Preparation and Characterization of Metal Soap Nanofilms. Master Thesis, Graduate School of Engineering Sciences of İzmir Institute of Technology, 2005.

Received for review September 14, 2009 Revised manuscript received November 12, 2009 Accepted December 24, 2009

IE901437D 